\title{
Bibliographie Supplémentaire
}

\section{a) Livres et articles d'exposition}

[C] J. Contes, $p$-adic $L$-functions and Iwasawa's theory, Algebraic Number Fields, A. Fröhlich ed., 269-353, Academic Press, London, 1977.

[I] K. Iwasawa, Lectures on $p$-adic $L$-functions, Annals of Mathematic Studies, Number 74, Princeton University Press, 1972.

[L 1] S. Lang, Cyclotomic Fields, Graduate Texts in Mathematics, Number 59, Springer-Verlag, New York, 1978.

[L 2] S. Lang, Cyclotomic Fields II, Id., Number 69, 1980.

[L 3] S. LANG, Units and class groups in number theory and algebraic geometry, Bull. A. M. S. 6, 3 (1982), 253-316.

[R] K. RibEt, Fonctions $L p$-adiques et théorie d'Iwasawa (notes de $\mathrm{Ph}$. Satgé), Publications Mathématiques d'Orsay, 79. 01, 1979.

[W] L. C. Washington, Introduction to cyclotomic fields, Graduate Texts in Mathematics, Number 83, Springer-Verlag, New York, 1982.

\section{b) Articles}

[C 1] J. Coates, The work of Mazur and Wiles on cyclotomic fields, Sém. Bourbaki, exp. $n^{\circ} 575$, juin 1981, 23 p.; Lecture Notes in Math. $n^{\circ}$ 901, Springer-Verlag, Berlin, 1981.

[Fr] E. Friedman, Ideal Class Groups in Basic $\mathbf{Z}_{p_{1}} \times \ldots \times \mathbf{Z}_{p_{\text {e }}}$ Extensions of Number Fields, Invent. Math. 65 (1982), 425-440.

[Fu] Ph. FurtwängLER, Über die Klassenzahlen der Kreisteilungskörper, J. reine angew. Math. 140 (1911), 29-32.

[F-G] B. Ferrero, R. Greenberg, On the Behavior of $p$-adic $L$-Functions at $s=0$, Invent. Math. 50 (1978), 91-102.

[F-W] B. Ferrero, L. C. Washington, The Iwasawa invariant $\mu_{p}$ vanishes for abelian number fields, Ann. of Math. 109 (1979), 377-395.

[GG 1] G. Gras, Sur la construction des fonctions $L$-adiques abéliennes, Sém. D. P. P., Paris, exp. no 22 (1978-1979), 20 p.; voir aussi:

[GG 2] G. Gras, Canonical divisibilities of values of $p$-adic $L$-functions, Journées Arithmétiques 1980, J. V. Armitage ed., Lecture Notes of the London Math. Soc. 56, Cambridge University Press, 1982.

[GGMN] G. et M.-N. Gras, Calcul du nombre de classes et des unités des extensions abéliennes réelles de Q, Bull. Sc. Math. 101 (1977), 97-129.

[Gi] R. Gillard, Remarques sur les unités cyclotomiques et les unités elliptiques, J. Number Th. 11 (1979), 21-48.

[Go] D. M. GoldFeld, The Class Number of Quadratic Fields and the Conjectures of Birch and Swinnerton-Dyer, Ann. Scuola Norm. Sup. Pisa, Cl. Sci. (4) 3 (1976), 624-663.

[Gr] R. Greenberg, On $p$-adic $L$-functions and cyclotomic fields II, Nagoya Math. J. 67 (1977), 139-158.

[HY 1] M. Hirabayashi, K. Yoshino, On the Relative Class Number of the Imaginary Abelian Number Field I, Memoirs of the College of Liberal Arts, Kanazawa Medical University, vol. 9 (1981), 5-53.

[HY 2] - M. Hirabayashi, K. Yoshino, On the Relative Class Number of the Imaginary Abelian Number Field II, Ibid., vol. 10 (1982), 33-81. 
[I 1] K. Iwasawa, On $\Gamma$-extensions of algebraic number fields, Bull. Amer. Math. Soc. 65 (1959), 183-226.

[I 2] K. Iwasawa, On $\mathbf{Z}_{l}$-extensions of algebraic number fields, Ann. of Math. 9x (1973), 246-326.

[I 3] K. Iwasawa, A class number formula for cyclotomic fields, Ann. of Math. 76 (1962), 171-179.

[K-Le] T. Kubota, H. W. Leopoldt, Eine $p$-adische Theorie der Zetawerte. Teil I: Einführung der $p$-adischen Dirichletschen $L$-Funktionen, J. reine angew. Math. 214/215 (1964), 328-339.

[Ku] D. S. KUBERT, The 2-divisibility of the class number and the Stickelberger ideal, Bull. Soc. Math. France, à paraître.

[Le 1] H.W.LEOPOLDT, Ubber Einheitengruppe und Klassenzahl reeller abelscherZahlkörper, Ábh. Deutsch. Akad. Wiss. Berlin, Kl. Math. 1953, n² 2(1954).

[Le 2] H. W. Leopoldt, Eine Verallgemeinerung der Bernoullischen Zahlen, Ahh. Math. Sem. Univ. Hamburg 22 (1958), 131-140.

[vd L] F. J. van der LINDEN, Class Number Computations of Real Abelian Number Fields, Math. Comp. 39 (1982), 693-707.

[Mr] J. Martinet, Petits discriminants des corps de nombres, Journées Arithmétiques 1980, J. V. Armitage ed., Lecture Notes of the London Math. Soc. 56, Cambridge University Press, 1982.

[Ms] J. MasLey, Odlyzko bounds and class number problems, Algebraic Number Fields, A. Fröhlich ed., 465-474, Academic Press, London, 1977.

[M-W] H. L. Montgomery, P. J. Weinberger, Notes on small class numbers, Acta Arith. 24 (1973-1974), 529-542.

[M-Wi] B. Mazur, A. Wiles, Class fields of abelian extensions of $\boldsymbol{Q}$, Invent. Math. 76 (1984), 179-330.

[Or] B. ORIAT, Relation entre les 2-groupes des classes d'idéaux aux sens ordinaire et restreint de certains corps de nombres, Bull. Soc. Math. France 104 (1976), 301-307.

[P] G. Portou, Sur les petits discriminants, Sém. D. P. P., Paris, exp. no 6 (1976-1977), $17 \mathrm{p}$.

[R 1] K. Rrbet, A modular construction of unramified $p$-extensions of $\mathbf{Q}\left(\mu_{p}\right)$, Invent. Math. 34 (1976), 151-162.

[R 2] K. RIBET, $p$-adic $L$-functions attached to characters of $p$-power order, Sém. D. P. P., Paris, exp. no 9 (1977-1978), 8 p.

[Sch 1] C.-G. Scнмid, Größencharaktere und Relativklassenzahl abelscher Zahlkörper, J. Number Th. 11 (1979), 128-159.

[Sंch 2] C.-G. Schmid, On Ray Class Annihilators of Cyclotomic Fields, Invent. Math. 66 (1982), 215-230.

[Se] J-P. Serre, Classes des corps cyclotomiques (d'après K. Iwasawa), Sém. Bourbaki, exp. no 174 (1958), 11 p.

[Si 1] W. M. Sinnotr, On the Stickelberger ideal and the circular units of a cyclotomic field, Ann. of Math. 108 (1978), 107-134.

[Si 2] W. M. SnNotr, On the Stickelberger ideal and the circular units of an abelian field, Invent. Math. 62 (1980), $181-234$.

[S-S] K. Selucky, L. Skula, Irregular imaginary fields, Arch. Math. 2, Scripta Fac. Sci. Nat. Ujep Brunensis (= Brno) XVII (1981), 95-112.

[St 1] H. M. StaRK, On the "Gap" in a Theorem of Heegner, J. Number Th. 1 (1969), 16-27. 
[St 2] H. M. StakK, On complex quadratic fields with Class-Number Two, Math. of Comp. 29 (1975), 289-302.

[W 1] L. C. Washington, The Non $p$-Part of the Class Number in a Cyclotomic $\mathbf{Z}_{p}$-Extension, Invent. Math. 49 (1979), 87-97.

[Wi] A. Wiles, Modular curves and the class group of $\mathbf{Q}\left(\zeta_{p}\right)$, Invent. Math. 58 (1980), 1-35. 
